\title{
Rapid assessment of knowledge, attitudes, practices, and risk perception related to the prevention and control of Ebola virus disease in three communities of Sierra Leone
}

\author{
Hai Jiang ${ }^{1,3+}$, Guo-Qing Shi ${ }^{2,3+}$, Wen-Xiao Tư ${ }^{2,3}$, Can-Jun Zheng ${ }^{3}$, Xue-Hui Lai ${ }^{3}$, Xin-Xu Li ${ }^{3}$, Qiang Wei ${ }^{3}$, Mei Li ${ }^{3}$, \\ Li-Quan Deng ${ }^{3}$, Xiang Huo ${ }^{3}$, Ming-Quan Chen ${ }^{3}$, Feng $\mathrm{Xu}^{3}$, Long-Jie $\mathrm{Ye}^{3}, \mathrm{Xi}^{-C h e n ~ B a i}{ }^{3}$, Tong-Nian Chen ${ }^{3}$, \\ Shao-Hua Yin ${ }^{3}$, Thomas T. Samba ${ }^{4^{*}}$ and Xiao-Feng Liang ${ }^{2,3^{*}}$
}

\begin{abstract}
Background: The recent outbreak of the Ebola virus disease (EVD) in Sierra Leone has been characterized by the World Health Organization as one of the most challenging EVD outbreaks to date. The first confirmed case in Sierra Leone was a young woman who was admitted to a government hospital in Kenema following a miscarriage on 24 May 2014. On 5 January 2015, intensified training for an EVD response project was initiated at the medical university of Sierra Leone in Jui. To understand the knowledge, attitudes, practices, and perceived risk of EVD among the public, especially after this training, a rapid assessment was conducted from 10 to 16 March 2015.

Methods: Interviews were conducted with 466 participants based on questionnaires that were distributed from 10 to 16 March 2015 by cluster sampling in three adjacent communities, namely Jui, Grafton, and Kossoh Town, in the Western Area Rural District of Sierra Leone.

Results: It was found that knowledge about EVD was comprehensive and high. Positive attitude towards prevention was found to be satisfactory. Nearly all participants knew the reporting phone number 117 and had reported some change in behavior since learning about Ebola. More than half (62 \%) of the participants had a history of travelling to urban areas, which increases the risk of infection. The multivariable logistic regression analysis showed that community and occupation were variables associated with perceived risk of EVD.
\end{abstract}

Conclusions: Our study showed that community level social mobilization and community engagement were an effective strategy in the special context.

Keywords: Knowledge, Attitude, Practice, Risk perception, ITERP, Ebola, Sierra Leone

\footnotetext{
*Correspondence: ttsamba@yahoo.com; liangxf@chinacdc.cn

${ }^{\dagger}$ Equal contributors

${ }^{4}$ District Health Management Team, Western Area, Ministry of Health and

Sanitation, Freetown, Sierra Leone

${ }^{2}$ Chinese Center for Disease Control and Prevention, Beijing 102206, China

Full list of author information is available at the end of the article
} 


\section{Multilingual abstracts}

Please see Additional file 1 for translations of the abstract into the six official working languages of the United Nations.

\section{Background}

The recent outbreak of Ebola virus disease (EVD) in Sierra Leone has been characterized by the World Health Organization as one of the most challenging EVD outbreaks to date $[1,2]$. The first confirmed case in Sierra Leone was a young woman who was admitted to a government hospital in Kenema following a miscarriage on 24 May 2014 [3] There have been 8590 cumulative cases attributed to EVD as of 30 April 2015from WHO [4]. The Western Area Rural District of Sierra Leone is a main area of interest with high risk of Ebola transmission [5].

On 5 January 2015, intensified training for an EVD response project (ITERP) was initiated at the medical university of Sierra Leone in Jui. The project's overall goal is to help the three administrative villages (Jui, Grafton and Kossoh Town) to strengthen the capacity of EVD control, improve the network for the prevention and treatment of infectious diseases, effectively control the spread of EVD in the community, and explore sustainable infectious disease prevention and control strategies and measures. Village leaders, community leaders, religious leaders, and community volunteers from some local and administrative villages have been trained to improve the public's awareness in order to change behaviors towards EVD control. The ITERP was undertaken in three main wards, namely Grafton, Kossoh Town, and Jui, where 42749 people lived in 9406 households, as of early 2015 [6].

Strategies for reducing Ebola cases to zero include detecting Ebola cases in a timely fashion, completely tracing and managing contacts, implementing safe and dignified burials, and the prevention and control of infections [7]. The first step is to engage social mobilization by involving community leaders and activists that can help improve the public's awareness, attitudes, and practices towards EVD control [8]. The district health management team of the Western Area Rural District and the public health team from China continue to place a major focus on educating the public on how to prevent the transmission of EVD, as well as encouraging people to promptly seek medical care in the event that they experience signs and symptoms associated with the disease. Despite these efforts, public education and social mobilization campaigns have been met with varied resistance from communities.

During ITERP, it was found that some people still engage in poor behaviors, including an unwillingness to report Ebola, a preference for traditional healing, and unsafe burials. Willingness to report Ebola needs to be further strengthened in communities. To grasp community knowledge, attitudes, and behavior, especially in terms of reporting awareness, reporting phone numbers, and risk perception related to Ebola control and to identify barriers that hinder the containment of the EVD epidemic, 30 social mobilizers from Jui, Grafton, and Kossoh Town conducted a questionnaire survey with the public.

\section{Methods}

House to house survey (Additional file 2) was conducted by 30 trained social mobilizers, separated into the three communities from 10 to 16 March 2015. A cluster sampling design was used in the study. The survey sample comprised all 35 villages in Jui (13), Kossoh Town (5), and Grafton (17). Random sampling was used to select 466 households for interviews. The household selection procedure in each village was as follows: A) Select 3-4 households in the north, south, east, and west of each village. Randomly select the first household in each direction and then choose the next-door neighbor, and so on. Members from at least 12 households were successfully interviewed in each village. B) Randomly select one eligible family member (between the ages of 20 and 60) from each selected household. C) Make

Table 1 Sociodemographic characteristics of 466 participants in three communities of Sierra Leone, 2015

\begin{tabular}{ll}
\hline Variable & $N(\%)$ \\
\hline Community & \\
Kossoh town & $79(16.95)$ \\
Jui & $160(34.33)$ \\
Grafton & $227(48.71)$ \\
Sex & \\
Male & $224(48.07)$ \\
Female & $242(51.93)$ \\
Occupation & \\
Student & $23(4.93)$ \\
Teacher & $35(7.51)$ \\
Company staff & $37(7.94)$ \\
Government staff & $62(13.30)$ \\
Other & $71(15.24)$ \\
Petty trading & $97(20.81)$ \\
Businessperson & $147(31.54)$ \\
Education & \\
Primary school & \\
High school & $62(13.30)$ \\
Illiterate & $74(15.88)$ \\
University & $98(21.03)$ \\
Junior high school & $103(22.10)$ \\
Chion & $139(27.68)$ \\
\hline Muslistian & $258(55.37)$ \\
\hline
\end{tabular}




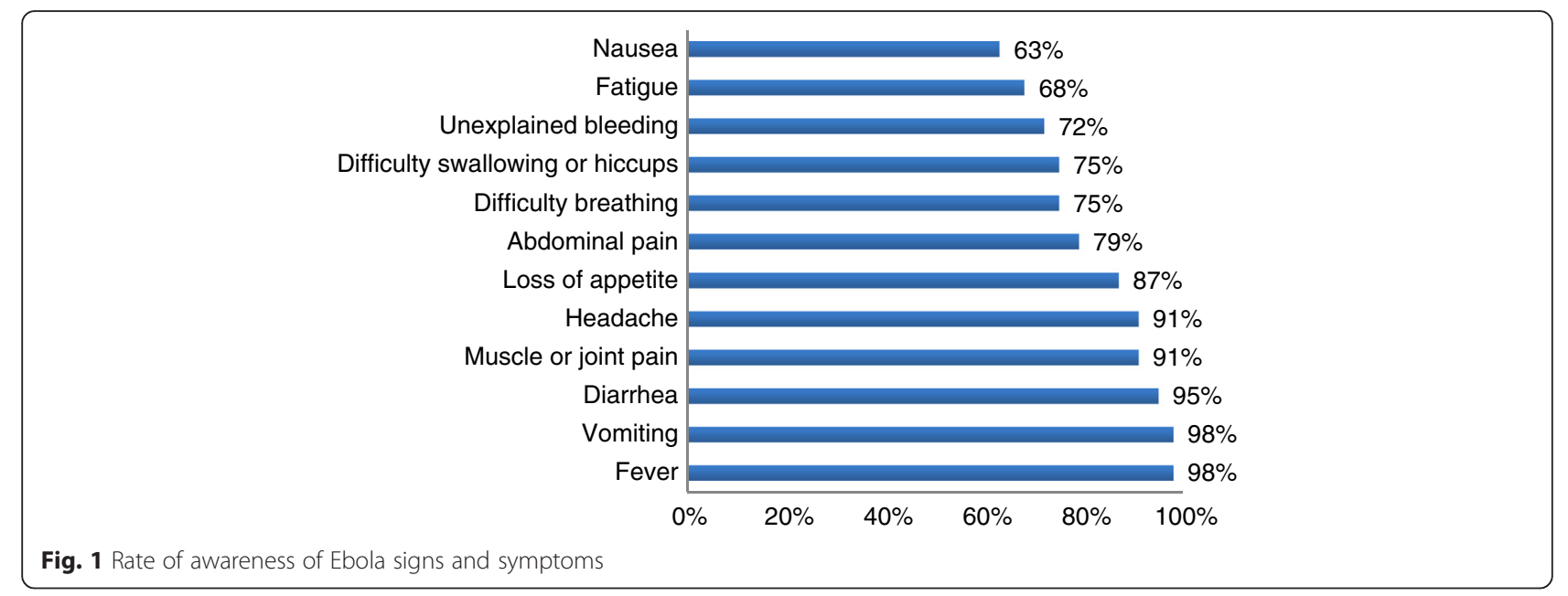

sure to record participants' valid phone numbers on the questionnaire.

About $5 \%$ of questionnaires were checked for the quality of assessment. Risk perceptions were operationalized by asking participants whether they were at risk of contracting EVD and how they perceive their personal probability of acquiring EVD on three levels: high, medium, and low. Risk perceptions were evaluated in the following scenarios: at work, in public places and at communities. "Perceived personal probability of infection" describes participants' estimation of the actual risk for infection.

To test the differences among the variables, we used the $\chi^{2}$ test for categorical variables (community, occupation, education level, ever been to seaside, getting Ebola information from billboards, and getting Ebola information from brochures)relating to concern about EVD. In addition, we performed explorative multivariable logistic regression analyses to assess the risk perception and sociodemographic factors associated with concern about EVD. Analyses were performed using the SPSS software version 20.0 (IBM, USA).

This study was approved by the Ethics Committee of the district health management team of the Western Area
Rural District of Sierra Leone. All participants gave written informed consent before participating in the study.

\section{Results}

Sociodemographic characteristics

We interviewed 466 participants in the three communities. Slightly more than half were female and one third was businessperson. $27.68 \%$ was junior high school student and $55.37 \%$ was Muslim (see Table 1).

\section{Rate of awareness of Ebola signs and symptoms, transmission routes, and control measures}

With regards to symptoms, $98 \%$ of respondents knew that fever and vomiting are main symptoms of Ebola infections, $95 \%$ knew that diarrhea is a main symptom, and $72 \%$ knew that hemorrhage is also a main symptom (see Fig. 1).

As for transmission routes, $98 \%$ of the respondents thought that taking part in a traditional funeral is a main route of transmission. Other routes of transmission such as patient semen and breast milk as well as eating with patients, was known by $89 \%, 89 \%$, and $82 \%$, respectively. Nearly everyone (98-99 \%) reported some change

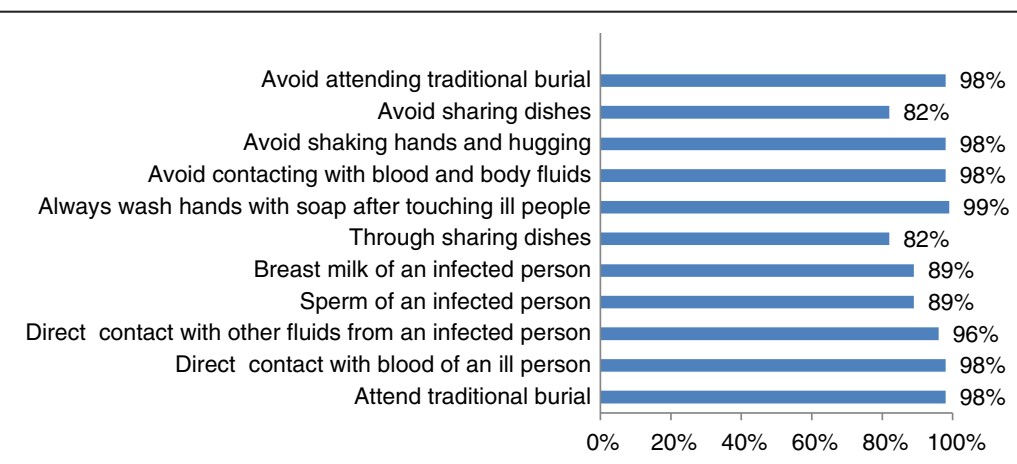

Fig. 2 Rate of awareness of Ebola transmission routes and control measures 


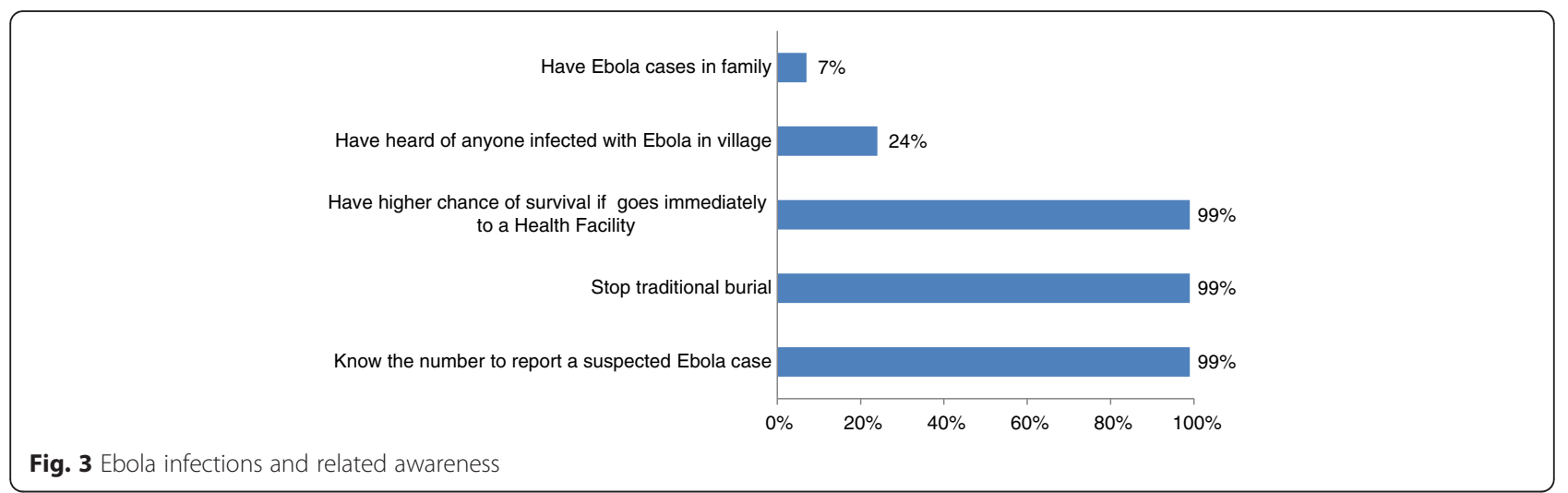

in behavior, such as avoid contacting with blood and body fluids, and avoid attending traditional burial and so on, since learning about Ebola (see Fig. 2).

\section{Ebola infections and related awareness}

Out of the respondents, 7 \% reported to have an Ebola patient in their home and $24 \%$ had heard of Ebola infections in their village. Nearly everyone knew the reporting phone number 117 and believes that a person with Ebola has a higher chance of survival if he/she gets treatment early $(99 \%)$. Nearly everyone said that they would call the number immediately if they found out that a neighbor was going to perform a traditional burial (99 \%) (see Fig. 3).

\section{Risk perception}

Only a small number $(10 \%)$ of respondents believe that they are at not at risk of contracting Ebola because they strictly abide by medical rules. Among $90 \%$ of respondents with infection risk, high, medium, and low risk of

Table 2 Association between the variables of community and occupation, and risk perception ${ }^{a}$

\begin{tabular}{llll}
\hline Characteristics & Odds ratios & $(95 \%$ Cl & $P$-value \\
\hline Community & & & \\
Jui & 0.29 & $(0.19,0.44)$ & $<.001$ \\
Kossoh Town & 0.05 & $(0.03,0.12)$ & $<.001$ \\
Grafton & Ref & & \\
Occupation & & & \\
Government staff & 0.62 & $(0.32,1.17)$ & 0.139 \\
Company staff & 1.30 & $(0.61,2.77)$ & 0.497 \\
Petty trading & 3.18 & $(1.83,5.54)$ & $<.001$ \\
Teacher & 1.25 & $(0.51,3.03)$ & 0.624 \\
Student & 0.61 & $(0.26,1.46)$ & 0.271 \\
Other & 0.94 & $(0.54,1.64)$ & 0.829 \\
Businessperson & Ref & & \\
\hline
\end{tabular}

${ }^{a}$ Multivariable logistic regression done by ordinal regression on SPSS 20.0 using the logit method infection ratios were $27 \%, 29 \%$, and $44 \%$, respectively. The multivariable logistic regression analysis showed that community and occupation were more likely to be associated with Ebola risk perception than the other variables (see Table 2).

\section{Mobility of the population}

The population is mobile: $62 \%$ (291) visited urban areas in the last three months and $25 \%$ visited daily on average, (see Figs. 4 and 5).

\section{Primary channel of receiving information about EVD}

Almost all respondents (98\%) prefer getting EVD-related information through the radio, making it the most favored method. Brochures are not available easily in remote villages, making it an unpopular method of information dissemination (see Fig. 6).

\section{Discussion}

As large-scale community-based education on Ebola prevention was conducted, knowledge about EVD was found to be comprehensive and high in the communities studied, and the positive attitude towards prevention was found to be satisfactory. Comprehensive

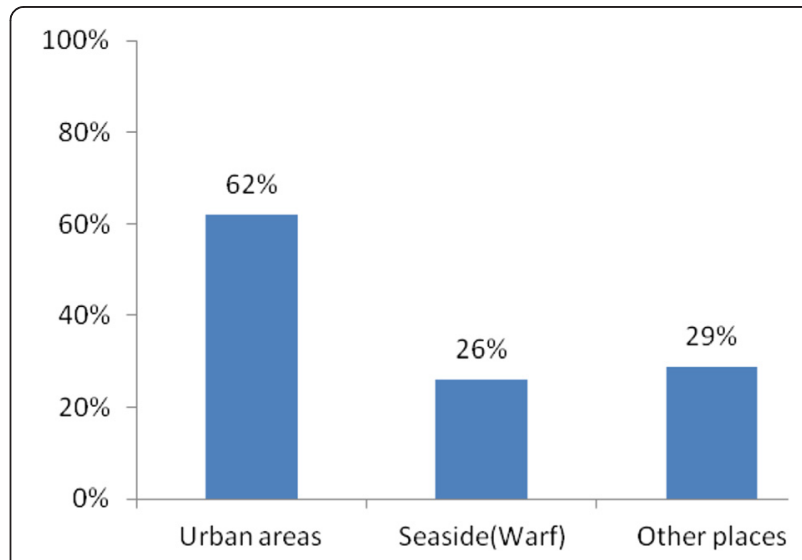

Fig. 4 Mobility of the population in last three months 


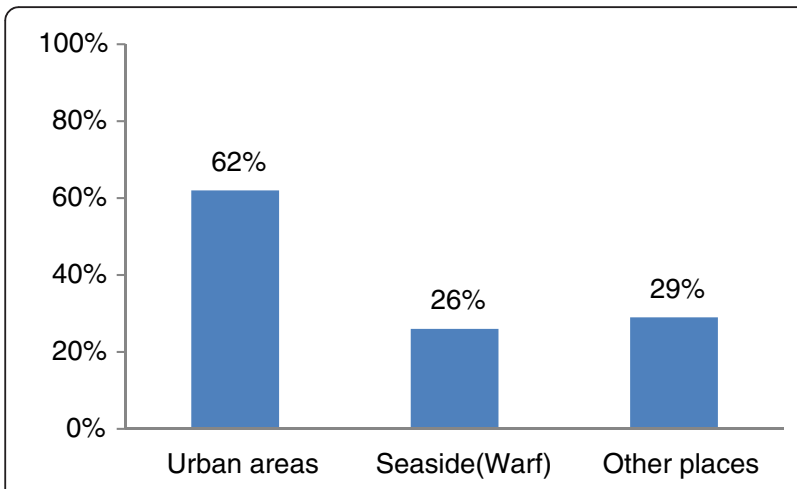

Fig. 5 Frequency of going to urban areas

knowledge is a critical component for increasing the likelihood of adopting promoted prevention strategies and medical-seeking behaviors. As for mobility, $62 \%$ of participants had a history of travelling to urban areas, which may increase the risk of infection.

Before this investigation, a baseline survey conducted on Ebola awareness showed that the rates of awareness of symptoms and transmission routes were $76 \%$ and $82 \%$, respectively (unpublished). During ITERP, the training effectiveness was obvious. The training increased awareness of EVD control and prevention, as well as community engagement. It also established a mechanism for coordination and cooperation between the community and a professional team.

As expected, awareness of knowledge, attitudes, and practices related to EVD prevention and control among the participants was very high. This response might be attributable to the fact that individuals gained key information through the intensified education and mobilization [9]. For example, nearly everyone knew the number to call to report a suspected EVD case and to stop a traditional burial. Nearly everyone also reported some change in behavior since learning about Ebola.

The percentage of people reporting that they wash their hands with soap after touching ill people is high (99 \%) and the percentage of people reporting that they avoid physical contact is also high (98\%). The reason why some residences do not report and/or still partake in unsafe burial practices seems to be related to risk perceptions. Those who felt that they were not at risk were unwilling to take action to change their behaviors. Reported risk perceptions are related to community and occupation. If real Ebola cases are reported in a community, people may have a higher perception of the actual risk for infection. The differences between occupations can be understood because higher mobility through urban areas and villages enhanced the infection risk For future campaigns, community education should be emphasized, not only to let people know how to prevent illness, but also why to prevent it, and to demonstrate the existence of risks [10].

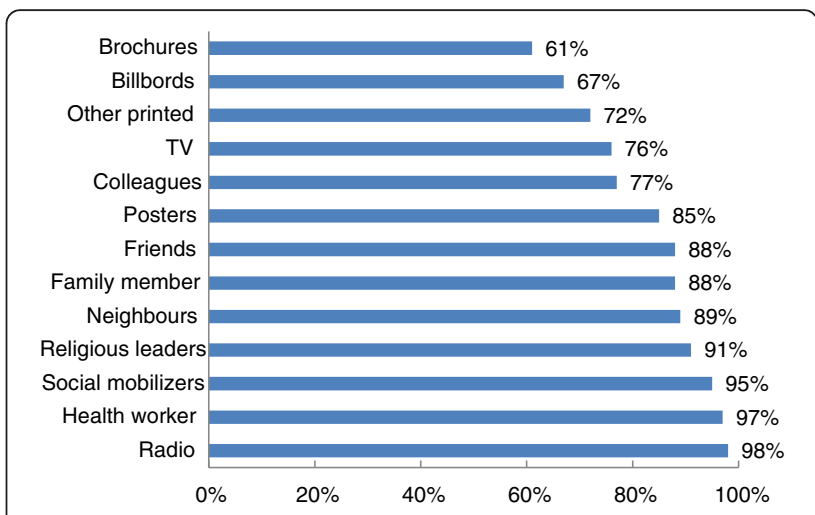

Fig. 6 Primary channel of receiving information about EVD

During ITERP, the Chinese public health training team strengthened health education, community mobilization, case detection and management, and close contact tracing. Through multiple stages of intensive training, personnel received a significant boost. After this survey, a third public health and training team launched a big round of 10000 brochures distribution activities, which will provide an effective weapon to win the battle for zero Ebola cases.

This study had some limitations. Restricted regional data collection might not represent the perceptions of the general population in the Western Area Rural District. Furthermore, because the investigators were social mobilizers, their level of knowledge of EVD might have affected the perceptions of the interviewees. The design of the sample size did not take into account the need for a multifactor analysis, so the results might be biased.

\section{Conclusion}

In summary, knowledge about EVD was found to be comprehensive and high in this study. Positive attitude towards prevention was found to be satisfactory. However, it is still urgent to further strengthen public education on the symptoms and modes of transmission of Ebola in all villages. Our study showed that community level social mobilization and community engagement were an effective strategy in the special context.

\section{Additional files}

Additional file 1: Multilingual abstracts in the sex official working languages of the United Nations. (PDF $246 \mathrm{~kb}$ )

Additional file 2: Questionnaire on Ebola knowledge, attitudes, practices, and risk perception in three communities of Sierra Leone, 2015. (DOCX 34 kb)

Abbreviations

EVD: Ebola virus disease; ITERP: intensified training for an EVD response project. 


\section{Acknowledgments}

We are extremely grateful for the technical guidance and commitment of the district health management team of Western Area Rural District in Sierra Leone. Likewise, we extend our sincere gratitude to the data collection mobilizers and supervisors whose diligent efforts ensured reliable and quality outputs. ITERP was supported by the National Health and Family Planning Commission and Ministry of Commerce, China.

\section{Authors' contributions}

HJ, GQS, WXT, and XFL conceived and designed the study, HJ, CJZ, XH, ML, TNC, QW, XCB, LJY, and SHY organized the survey. LQD, XHL, MQC, FX, and WXT analyzed the data. HJ and GQS wrote the first draft of the paper. TTS provided constructive opinions and suggestions. XFL provided strategic advices and assisted with editing of the manuscript. All authors read and approved the final version of the paper.

\section{Competing interests}

The authors declare that they have no competing interests.

\section{Author details}

'State Key Laboratory for Infectious Disease Prevention and Control, Collaborative Innovation Center for Diagnosis and Treatment of Infectious Diseases, National Institute for Communicable Disease Control and Prevention, Beijing 102206, China. ${ }^{2}$ Chinese Center for Disease Control and Prevention, Beijing 102206, China. ${ }^{3}$ ITERP, Beijing 102206, China. ${ }^{4}$ District Health Management Team, Western Area, Ministry of Health and Sanitation, Freetown, Sierra Leone.

Received: 5 November 2015 Accepted: 4 May 2016

Published online: 06 June 2016

\section{References}

1. WHO. Public Health Emergency of International Concern Declaration on 8th August. 2014. Available: http://www.who.int/mediacentre/news/statements/ 2014/ebola-20140808/en/.

2. World Health Organization Ebola Response Team. Ebola virus disease in West Africa - the first 9 months of the epidemic and forward projections. N Engl J Med. 2014;371:1481-95.

3. Meredith GD, Ilana JS. Ebola Viral Disease Outbreak — West Africa, 2014. Morbidity and Mortality Weekly Report (MMWR). 2014,63(25);548-551.

4. WHO. Ebola Situation Reports-. 2015. http://apps.who.int/ebola/ebolasituation-reports (Accessed on 15 Nov 2015).

5. Chan M. Ebola Virus Disease in West Africa-No Early End to the Outbreak. N Engl J Med. 2014:371:1183-5.

6. Richards P, Amara J, Ferme MC, Kamara P, Mokuwa E, Sheriff Al, et al. Social pathways for Ebola virus disease in rural Sierra Leone, and some implications for containment. PLoS Negl Trop Dis. 2015;9(4):e3567.

7. Focus 1000 -Technical report. Study on public knowledge,attitudes, and practices relating to Ebola Virus Disease (EVD) prevention and medical care in Sierra Leone; 2014. Available: http://newswire.crs.org/wp-content/ uploads/2014/10/Ebola-Virus-Disease-National-KAP-Study-Final-Report_-fin.

8. Iliyasu G, Ogoina D, Otu AA, Dayyab FM, Ebenso B, Otokpa D, Rotifa S, Olomo WT, Habib AG. A Multi-Site Knowledge Attitude and Practice Survey of Ebola Virus Disease in Nigeria. PLoS One. 2015;10(8):e0135955.

9. Kobayashi M, Beer KD, Bjork A, Chatham-Stephens K, Cherry CC, Arzoaquoi S, Frank W, Kumeh O, Sieka J, Yeiah A, Painter JE, Yoder JS, Flannery B, Mahoney F, Nyenswah TG. Community Knowledge, Attitudes, and Practices Regarding Ebola Virus Disease - Five Counties, Liberia, September-October, 2014. MMWR Morb Mortal Wkly Rep. 2015;64(26):714-8.

10. Rübsamen N, Castell S, Horn J, Karch A, Ott JJ, Raupach-Rosin H, Zoch B, Krause G, Mikolajczyk RT. Ebola risk perception in Germany, 2014. Emerg Infect Dis. 2015;21(6):1012-8.

\section{Submit your next manuscript to BioMed Central and we will help you at every step:}

- We accept pre-submission inquiries

- Our selector tool helps you to find the most relevant journal

- We provide round the clock customer support

- Convenient online submission

- Thorough peer review

- Inclusion in PubMed and all major indexing services

- Maximum visibility for your research

Submit your manuscript at www.biomedcentral.com/submit 